\title{
VARREDORES DE RUA: ACIDENTES DE TRABALHO OCORRIDOS NA CIDADE DE RIBEIRÃO PRETO, ESTADO DE SÃO PAULO, BRASIL*
}

\author{
Edilene Aparecida Araújo da Silveira** \\ Maria Lúcia do Carmo Cruz Robazzi*** \\ Margarita Antonia Villar Luis****
}

SILVEIRA, E.A.A.da; ROBAZZI, M.L.do C.C.; LUIS, M.A.V. Varredores de rua: acidentes de trabalho ocorridos na cidade de Ribeirão Preto, Estado de São Paulo, Brasil. Rev.latino-am.enfermagem, Ribeirão Preto, v. 6, n. 1, p. 71-79, janeiro 1998.

O trabalho executado pelos garis ou varredores de rua é de remoção de detritos e entulhos presentes nos logradouros públicos. É considerado insalubre, pelo contato íntimo que expõe os trabalhadores a agentes presentes nos lixos urbanos. Como realizam suas tarefas em ambientes abertos, encontram-se submetidos a diversos tipos de agressões. O presente estudo teve como objetivo geral investigar os acidentes de trabalho registrados, ocorridos entre os garis, na cidade de Ribeirão Preto, Estado de São Paulo, durante os anos de 1993 e 1994, e como objetivos especificos verificar: o número de trabalhadores acidentados e de acidentes de trabalho notificados; os dados de identificação dos acidentados e da empresa e os dados especificos relacionados aos acidentes de trabalho. Para a concretização dos objetivos, foram analisadas as informações contidas nas Comunicações de Acidentes do Trabalho arquivadas no Instituto Nacional de Seguro Social, no Escritório Regional de Saúde (ERSA) local e na empresa de limpeza urbana, empregadora dos garis. Os resultados foram divulgados ao empregador e ao ERSA, colocando-se os autores à disposição para discutir em conjunto, soluções para os problemas ocupacionais encontrados.

UNITERMOS: varredores de rua, acidentes de trabalho

\section{INTRODUÇÃO}

Para FERREIRA (1993), gari ou varredor é "o que ou quem varre..., o indivíduo que executa a varrição das ruas, sendo portanto empregado da limpeza pública". "Varre o local, utilizando diversos tipos de vassouras, para deixá-lo limpo; reúne ou amontoa a poeira, fragmentos e detritos, empregando o ancinho ou outros instrumentos, para recolhê-los; recolhe os montes de lixo, despejando-os em latões, cestos e outros depósitos apropriados, para facilitar a coleta e transporte. Pode transportar o lixo até o local de despejo". (BRASIL, Ministério do Trabalho, 1982). Assim o trabalho executado por estes indivíduos é importante, para deixar as cidades limpas e livres de eventuais enfermidades, que podem acontecer, em decorrência do acúmulo destes detritos.

Lixo é entendido por PINTO (1979), como sendo resíduos sólidos resultantes da atividade das aglomerações urbanas, sobras industriais ou domésticas que não possuem valor, utilidade ou não têm mais significação econômica. Complementa SEWELL (1978) que o tipo e qualidade dos resíduos sólidos são determinados pelos hábitos culturais e pelas instituições econômicas.

A medida que a população aumenta, no entanto, a tarefa de recolher o lixo torna-se complexa, pois maior quantidade de detritos são produzidos; além disso é considerada atividade insalubre em grau máximo, devido ao contato dos trabalhadores com agentes biológicos, presentes nos lixos recolhidos, conforme consta na Norma Regulamentadora $\mathrm{n}^{\circ} 15$, anexo 14 (SEGURANÇA..., 1995).

Percebe-se então que os garis estão sujeitos ao contato íntimo com estes resíduos. Como realizam seu trabalho a "céu aberto" (em praças, ruas e demais

\footnotetext{
* Este estudo é parte do projeto de pesquisa intitulado “A questão acidentária entre varredores de rua da cidade de Ribeirão Preto, Estado de São Paulo", contemplado com verba da FAPESP (Bolsa, modalidade Aperfeiçoamento), nos anos de 1994/1995. Foi apresentado no 25th International Congress on Occupational Health, realizado de 15 a 20 de setembro de 1996, em Estocolmo, Suécia

** Enfermeira, bolsista da FAPESP

*** Enfermeira do Trabalho. Professora Doutora da Escola de Enfermagem de Ribeirão Preto da Universidade de São Paulo. Orientadora do Projeto

**** Professora Doutora da Escola de Enfermagem de Ribeirão Preto da Universidade de São Paulo
} 
logradouros), encontram-se submetidos às radiações solares, à umidades ou climas secos, ao trânsito existente no horário de trabalho, à mordedura de animais soltos nas ruas, às variações de temperatura, entre outros tipos de agentes agressores. WINGAARDEN \& SMITH (1988) referem a existência do calor como risco ocupacional porque pode agravar ou causar o aparecimento de doenças renais, cardíacas e respiratórias. Realizando trabalho de varrição e limpeza de logradouros públicos, estes trabalhadores submetem-se ao calor e outras variações meteorológicas, como frio, chuvas, ventos, entre outras.

Durante a execução da limpeza das ruas são expostos também ao ruído provocado pelo barulho dos carros nas ruas, definido por BULHÕES (1976) como sendo o barulho percebido de maneira desagradável. A poeira aparece como outro problema a que o trabalhador pode encontrar-se exposto. STELMAN \& DAUM(1975) relatam que quando inspirada durante longos períodos, a poeira das ruas pode penetrar profundamente nos pulmões causando irritação crônica das mucosas. Estas condições de trabalho podem lhes favorecer a ocorrência de acidentes de trabalho e doenças, que possivelmente resultarão em prejuízos à sua saúde física e mental.

Diante da revisão de literatura que apontou apenas duas investigações sobre estes trabalhadores, na cidade de Ribeirão Preto, Estado de São Paulo: uma que retratava os riscos ocupacionais aos quais estão submetidos os garis (MARZIALE \& CARVALHO, 1989) e outra que enfatizava os desconforto que os mesmos sentiam, durante a jornada laboral (SHIMO, 1995), desenvolveu-se o presente estudo, que teve como objetivo geral investigar os acidentes de trabalho registrados, ocorridos entre os garis desta cidade, durante os anos de 1993 a 1994. Como objetivos específicos verificou-se: o número de trabalhadores acidentados e de acidentes de trabalho notificados; as características gerais dos indivíduos acidentados e da empresa contratante dos mesmos; os dados gerais relacionados às características do trabalho executado por estas pessoas e os dados específicos relacionados aos acidentes; tais como: as partes do corpo lesadas em sua decorrência e as causas dos mesmos.

Para a concretização dos objetivos, foram analisadas as diversas informações contidas nas Comunicações de Acidentes do Trabalho.

\section{MATERIAL E MÉTODO}

Constituiu-se objeto deste estudo os acidentes de trabalho (AT) ocorridos na região urbana da cidade de Ribeirão Preto, Estado de São Paulo, entre indivíduos que executavam a limpeza de ruas, parques, jardins e outros logradouros públicos, no período compreendido entre $1^{\circ}$ de janeiro de 1993 a 31 de dezembro de 1994. A coleta dos dados foi realizada:

a) no Setor de Pagamento de Benefícios de Acidentes de Trabalho do Instituto Nacional de Seguro Social (INSS), agência de Ribeirão Preto, através do levantamento de Comunicações de Acidentes de Trabalho (CAT);

b) na empresa responsável pela limpeza dos logradouros públicos, de caráter particular, onde foram encontradas outras CAT, referentes ao mesmo período, além das que haviam sido localizadas no INSS. Neste local obteve-se também as informações sobre as características gerais do trabalho executado pelos garis, bem como sobre a própria empresa;

c) no então denominado Escritório Regional de Saúde da cidade (ERSA), atual DIR (Divisão de Saúde), onde está sendo implantado um sistema de informatização das CAT, constituindo-se portanto o local onde os municípios vinculados a esta divisão, incluindose a cidade de Ribeirão Preto, encaminham estas comunicações. Buscou-se então no ERSA outras CAT, que não haviam sido encontradas no INSS e/ou na empresa.

As CAT encontradas relativas ao período destes dois anos foram copiadas, de modo idêntico às originais. Para a codificação das "causas" dos AT utilizou-se a Classificação Internacional de Doenças (1975), edição de 1992. As informações coletadas das CAT, foram colocadas em banco de dados específico (FOX-BASE CRUZADAD), criado especialmente para isto, já que o Sistema CAT para Vigilância Epidemiológica dos Acidentes e Doenças do Trabalho (SISCAT), utilizado na investigação de ALMEIDA et al. (1994), ainda não se encontra em atividade, com êxito no ERSA, nem nos demais programas de atendimento aos trabalhadores existentes na cidade.

O acesso à empresa, ao INSS e ao ERSA deu-se através de ofícios solicitando esta permissão e esclarecendo os objetivos do presente estudo. No INSS a coleta de dados iniciou-se no mês de junho de 1995 , prolongando-se durante mais um mês. No final de julho até meados de agosto, coletou-se os dados na empresa e no ERSA. Na empresa, além de copiar as CAT e obter as informações sobre a mesma e o tipo de trabalho executado pelos garis, procurou-se conhecer o montante de trabalhadores distribuídos por ano, para se ter noção da quantidade de acidentados em relação ao número total de empregados, nesta função.

\section{RESULTADOS E DISCUSSÃO}

Em relação ao número de AT e de garis acidentados, verificou-se que foram 44 acidentes 
registrados neste período de dois anos, sendo estas informações mostradas na figura a seguir.

Figura 1 - Distribuição de 44 AT entre varredores de rua na cidade de Ribeirão Preto (SP), nos anos de 1993 e 1994

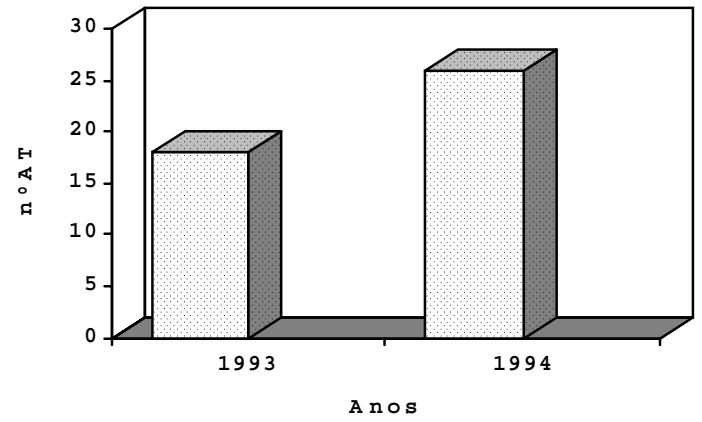

Cada trabalhador teve notificado um AT, constituindo-se portanto 44 os indivíduos acidentados. Ao se questionar a empresa sobre o número total de garis, empregados no período em questão, a mesma informou que não possuía com exatidão, a distribuição de número de empregados específicos por categoria, mas afirmou que cerca de $50 \%$ do total deles, em cada ano, exerciam a função de varredores de rua. Desta forma mostrou que em 1993 tinha 626 empregados, sendo 313 pertencentes a varrição. Destes, $18(5,8 \%)$ apresentaram AT registrados; no ano seguinte, contava com 466 empregados, sendo 233 garis e destes 26 sofreram AT $(11,2 \%)$. Estranha-se que uma empresa não tenha em seu poder registros de admissões, demissões e número de empregados por ano, determinados por categorias profissionais; o fato foi justificado como sendo conseqüência de freqüentes mudanças no corpo administrativo da mesma, o que prejudicou o arquivamento e a separação adequada destes dados.

Há um reduzido número de AT, em relação ao total de garis contratados pela empresa. Quando se consulta a literatura existente sobre garis e coletores de lixo (MARZIALE \& CARVALHO, 1989; PEREIRA, 1978; PINTO, 1979; ROBAZZI, 1984, 1991; SHIMO, 1995) constata-se que o tipo de trabalho executado por estas pessoas é realizado nas ruas das cidades, submetendo os trabalhadores a possibilidade de colisões com veículos, contactos íntimos que provocam ferimentos pelos objetos constantes nos lixos recolhidos, poeiras, agentes biológicos presentes nestes resíduos, além de mordeduras e recolhimentos de corpos de animais em putrefação, entre outras situações. Diante destes relatos, percebe-se que foram poucos os AT notificados no presente estudo.

Por outro lado sabe-se que no caso dos coletores de lixo, empregados da mesma empresa, nos anos de 1987 e 1988, houve subnotificações de acidentes, conforme evidenciado no estudo de ROBAZZI (1991). Assim, acredita-se que o número acidentário não expressivo apresentado pelos garis, em 1993 e 1994, ocorreu em decorrência da subnotificação destes eventos, que parece ser prática relativamente comum por parte, não só desta, mas de grande parte de empresas brasileiras.

Para SANTOS et al. (1990) "os acidentes de trabalho e doenças profissionais acometem a cada mês, milhares de trabalhadores. Os índices mostram-se superiores ao de qualquer epidemia que o país já vivenciou, refletindo as condições de organização do trabalho no Brasil". Também SANTOS et al. (1990) citando Possas, informaram que "em 1980, um estudo da Organização Internacional do Trabalho (OIT) mostrou dados que apontaram o Brasil, quando comparado a outros países industrializados, como aquele com maior número de óbitos na População Economicamente Ativa (PEA), evidenciando as condições de alta periculosidade dos ambientes de trabalho no país".

A não notificação de AT parece ser prática usual e então nem sempre o que os números oficiais demostram é a realidade encontrada no universo dos trabalhadores brasileiros. O conhecimento da existência da subnotificação é consenso entre autores como MACEDO (1980); MEDRADO FARIA (1987); POSSAS (1987) e MENDES (1986). Se no Brasil há maior número de óbitos entre a PEA, é de se supor que deve haver outra grande quantidade de acidentes e doenças, entre esta população, que não são notificados. Conforme foi evidenciado anteriormente a empresa subnotificava em 1987 e 1988 e provavelmente continuou a não informar os AT, nos anos mais recentes; acredita-se também que os acidentes que chegaram a ser notificados, provavelmente foram os mais graves e/ou difíceis de serem ocultados, tanto por parte da empresa, como por parte dos empregados acidentados.

Em relação as características individuais dos trabalhadores acidentados, nestes anos, as informações encontram-se apresentadas a seguir.

Tabela 1 - Distribuição de 44 trabalhadores da varrição acidentados de acordo com o sexo, na cidade de Ribeirão Preto (SP), nos anos de 1993 e 1994

\begin{tabular}{ccccccc}
\hline $\mathrm{N}^{\circ}$ & \multicolumn{2}{c}{ Sexo feminino } & \multicolumn{2}{c}{ Sexo masculino } & \multicolumn{2}{c}{ TOTAL } \\
\hline & $\mathrm{N}^{\circ}$ & $\%$ & $\mathrm{~N}^{\circ}$ & $\%$ & $\mathrm{~N}^{\circ}$ & $\%$ \\
1993 & 7 & 15,9 & 11 & 25,0 & 18 & 40,9 \\
1994 & 9 & 20,5 & 17 & 38,6 & 26 & 59,1 \\
\hline TOTAL & 16 & 36,4 & 28 & 63,6 & 44 & 100,0 \\
\hline
\end{tabular}

A maior parte destes empregados, nestes anos, pertencia ao sexo masculino; $36.3 \%$ tinham idade, entre 
31 a 40 anos; $25 \%$ entre 21 a 30 anos e $13.6 \%$ entre 18 a 20 anos. Segundo os empregados do Setor de Recursos Humanos da empresa, não há contratação de garis com idade inferior a 18 e nem acima de 45 anos, em virtude do trabalho que denota exigência física por parte dos empregados. Quanto ao estado civil, 52.3\% destas 44 pessoas eram solteiras, $43.2 \%$ casadas e as demais divorciadas ou viúvas.

Em relação aos dados de identificação da empresa e características do trabalho executado pelos varredores de ruas, na ocasião em que os dados foram coletados, obteve-se as seguintes informações: trata-se de uma empresa de caráter particular, terceirizada pelo departamento da Prefeitura Municipal responsável pela urbanização e saneamento da cidade, desde agosto de 1987 até a presente data. É a única empresa localizada no município encarregada dos serviços de varrição e coleta de lixo, bem como do recolhimento de entulhos de logradouros públicos, feiras livres e das ruas.

Para facilitar o serviço, ela dividiu a cidade em sete setores sendo dois noturnos e cinco diurnos. Os trabalhadores da varrição possuem como instrumentos de trabalho, vassouras com cerdas tipo piaçava, carrinhos metálicos com rodas pneumáticas, sacos de lixo e pás metálicas. Vassouras, pás e sacos de lixo permanecem acondicionados na parte posterior do carrinho. Como equipamentos de segurança, utilizam uniforme de algodão de espesso, do tipo calça comprida e jaleco de mangas longas, de coloração amarelo-laranja, com o logotipo da empresa estampado na parte posterior do jaleco. Acreditase que este tipo de roupa é excessivamente quente para indivíduos que trabalham nas ruas, sob as condições meteorológicas observadas costumeiramente na cidade de Ribeirão Preto, que chega apresentar picos de temperaturas superiores a $35^{\circ} \mathrm{C}$, em dias de verão. Para os que realizam jornada noturna, são distribuídos coletes refletores. A empresa informou que não fornece luvas ou sapatos impermeáveis aos trabalhadores.

Os garis percorrem os logradouros seguindo roteiros pré estabelecidos despejando os entulhos recolhidos nos carrinhos descritos anteriormente, valendo-se de seu esforço físico e dos instrumentos manuais supra mencionados. Trabalham cerca de oito horas por dia e recebem salário em torno de US\$ 183,0 (cento e oitenta e três dólares americanos) acrescido de US\$ 20,0 (vinte dólares americanos) relativos a insalubridade. Ganham também um vale-refeição de US\$ 67,0 (sessenta e sete dólares americanos).

Quando um destes indivíduos não comparece ao emprego, tem como perdas salariais as parcelas referentes ao dia da falta e ao domingo imediatamente seguinte à mesma. Como existem tais prejuízos pelas faltas, independente dos motivos, acredita-se que os empregados devam ausentar-se pouco e não notificar à chefia quando se acidentam, para não sofrerem reduções salariais. Ou seja, a própria empresa estimula o trabalhador a comparecer ao serviço, através desta prática. Reduzir parcelas de salário referentes ao adicional de insalubridade e de prêmio por assiduidade constituía-se em atitude comum adotada pelo departamento da Prefeitura Municipal citado anteriormente, conforme encontrou ROBAZZI (1984) e parece ter sido copiada pela empresa, terceirizada pelo mesmo.

Esta informou também que todos os meses são contratados vários garis, o que implica em troca de empregados, OLIVEIRA (1994), menciona que a economia brasileira apresenta a mais elevada rotatividade de mão de obra do mundo, denominando este comportamento como predatório. Em geral as empresas do país apresentam cerca de $30 \%$ de trabalhadores permanentes e $70 \%$ que são continuadamente trocados, contratando sazonalmente a mão de obra.

Tal comportamento por parte do empregador foi evidenciado por ROBAZZI (1991) pois em 1988 a empresa em questão também apresentou um elevado número de mudanças de trabalhadores, empregados da coleta de lixo (253 admitidos/demitidos/ano) alegando, na ocasião, que estas demissões foram necessárias pois os trabalhadores eram "ineficientes e incapazes de realizar as tarefas exigidas para aquele tipo de trabalho". No entanto verificou-se que estas pessoas eram "coincidentemente" demitidas após terem sofrido AT.

A empresa conta atualmente com um profissional médico, especialista na área de saúde do trabalhador, contratado a partir de novembro de 1994 e um auxiliar de enfermagem da mesma especialidade, admitido em janeiro de 1995. O ambulatório existente no local recebe e arquiva os atestados médicos e nele realizam-se procedimentos do tipo curativos, nos acidentados. No entanto, como os trabalhadores, tanto da varrição quanto da coleta de lixo realizam sua atividade essencialmente nas ruas da cidade, essa segunda função quase não acontece na empresa, dirigindo-se os acidentados diretamente aos hospitais mais próximos ao local onde se encontram trabalhando.

No dia da contratação, os garis são orientados sobre tópicos de segurança do trabalho, bem como sobre assuntos envolvendo recursos humanos. No dia seguinte iniciam seu trabalho nas ruas. O exame admissional é limitado a exame físico e entrevista e a empresa informou que exames periódicos e orientações repetem-se a cada seis meses aproximadamente, sem exames laboratoriais.

Os trabalhadores raramente vão até a empresa, exceto quando convocados. De suas residências, dirigemse diretamente ao setor onde trabalham e lá o encarregado os divide nas ruas, onde deverá ser realizado o serviço de varrição. A empresa mencionou que cada setor (região 
da cidade) possui um abrigo onde os garis podem tomar água, utilizar o sanitário e guardar seus instrumentos de trabalho. Como esses empregados em geral trabalham longe desses abrigos, na maioria das vezes torna-se difícil retornar aos mesmos. Caso precisem hidratar-se ou utilizar o sanitário, dirigem-se às residências ou casas comerciais. No caso de uso dos sanitários, é mais comum esperarem o término da jornada laboral e dirigirem-se a banheiros públicos, (particularmente os que trabalham na área central da cidade) ou satisfazerem suas necessidades fisiológicas na própria roupa, matagais ou terrenos baldios próximos de onde estão trabalhando. Esta realidade, provocando um evidente desconforto nos indivíduos, foi constatada por SHIMO (1995), em estudo realizado entre os garis da cidade.

Os empregados podem contar ainda com um sindicato que oferece assistência jurídica. Sobre este organismo, no entanto, o próprio empregador colocou que o mesmo "assessora mal" os trabalhadores, oferecendo um atendimento que denominou "desqualificado". Há também uma empresa de convênio médico à qual são encaminhados os que necessitam de assistência médica mais especializada, que o ambulatório da empresa não tem condições de oferecer.

Verificou-se também que a grande maioria dos acidentes ocorridos entre os garis, neste período de dois anos, foram considerados como sendo "típicos" ou "tipos" (94\% em 1993 e 96\% em 1994), ou seja, aconteceram durante o desenrolar da atividade laboral. Esta situação é compreensível de acontecer, considerando-se que os indivíduos trabalham com reduzidos equipamentos de proteção individual e em situação de desconforto físico, conforme já descrito anteriormente e comprovado por SHIMO (1995), o que pode favorecer a ocorrência de AT.

Mesmo provavelmente havendo subnotificação acidentária entre os garis, houve aumento dos AT, de 1993 em relação a 1994, conforme mostrou a primeira figura. Este fato pode ser explicado pelo aumento de número de pessoas, a cada ano, que passou a trabalhar neste serviço, elevando-se assim a possibilidade de ocorrência acidentária. Por outro lado a presença de profissionais com especialidade na área de saúde no trabalho, possivelmente pode ter começado a contribuir com a existência de maiores critérios, por parte da empresa, que passou a registrar em quantidade mais elevada os acidentes, antes não notificados. Pode-se supor também que os AT registrados de 1994 foram considerados mais graves que os de 1993, não sendo possível omiti-los.

Quanto as causas dos AT, de acordo com a Classificação Internacional de Doenças, citada anteriormente, encontram-se distribuídas nas tabelas a seguir.
Tabela 2 - Distribuição de 18 AT entre 18 varredores de rua segundo as causas ou objetos causadores de acidente na cidade de Ribeirão Preto (SP) no ano de 1993

\begin{tabular}{|c|c|c|}
\hline \multirow[t]{2}{*}{ CAUSAS } & \multicolumn{2}{|c|}{$\begin{array}{l}\text { ACIDENTES DE } \\
\text { TRABALHO }\end{array}$} \\
\hline & $\mathrm{N}^{\circ}$ & $\%$ \\
\hline $\begin{array}{l}\text { Acidente por colisão com veículo a } \\
\text { motor }\end{array}$ & 4 & 22,2 \\
\hline $\begin{array}{l}\text { Queda no mesmo nivel por } \\
\text { escorregão/tropeção, ou de um nível } \\
\text { a outro }\end{array}$ & 4 & 22,2 \\
\hline $\begin{array}{l}\text { Impacto acidental causado porqueda } \\
\text { de objeto }\end{array}$ & 3 & 16,7 \\
\hline $\begin{array}{l}\text { Acidente causado por objeto } \\
\text { cortante/perfurante }\end{array}$ & 3 & 16,7 \\
\hline $\begin{array}{l}\text { Impacto acidental contra objeto } \\
\text { estacionário }\end{array}$ & 2 & 11,1 \\
\hline $\begin{array}{l}\text { Acidente causado por máquina } \\
\text { agrícola }\end{array}$ & 1 & 05,5 \\
\hline $\begin{array}{l}\text { Acidente devido a aprisionamento } \\
\text { entre objetos }\end{array}$ & 1 & 05,5 \\
\hline TOTAL & 18 & 99,9 \\
\hline
\end{tabular}

Tabela 3 - Distribuição de 26 AT entre 26 varredores de rua segundo as causas ou objetos causadores de acidente na cidade de Ribeirão Preto (SP) no ano de 1994

\begin{tabular}{|c|c|c|}
\hline \multirow[t]{2}{*}{ CAUSAS } & \multicolumn{2}{|c|}{$\begin{array}{l}\text { ACIDENTES DE } \\
\text { TRABALHO }\end{array}$} \\
\hline & $\mathrm{N}^{\circ}$ & $\%$ \\
\hline $\begin{array}{l}\text { Acidente causado por objeto } \\
\text { cortante/perfurante }\end{array}$ & 8 & 30,8 \\
\hline $\begin{array}{l}\text { Acidente com colisão com veículo a } \\
\text { motor }\end{array}$ & 6 & 23,1 \\
\hline $\begin{array}{l}\text { Queda no mesmo nivel por } \\
\text { escorregão/tropeção }\end{array}$ & 3 & 11,5 \\
\hline Pisada em objeto estacionário & 3 & 11,5 \\
\hline $\begin{array}{l}\text { Acidente causado por máquina não } \\
\text { especificada }\end{array}$ & 2 & 07,7 \\
\hline $\begin{array}{l}\text { Acidente ocorrido ao descer de } \\
\text { veículo a motor }\end{array}$ & 1 & 03,8 \\
\hline $\begin{array}{l}\text { Excesso de exercício e movimentos } \\
\text { extenuantes }\end{array}$ & 1 & 03,8 \\
\hline $\begin{array}{l}\text { Impacto acidental causado por queda } \\
\text { de objeto }\end{array}$ & 1 & 03,8 \\
\hline $\begin{array}{l}\text { Penetração acidental de corpo } \\
\text { estranho }\end{array}$ & 1 & 03,8 \\
\hline TOTAL & 26 & 99,8 \\
\hline
\end{tabular}


Observa-se que no ano de 1993 a maior parte dos acidentes foi causada por colisões com veículo a motor e quedas (22,2\% cada um), seguidos em ordem decrescente por impacto acidental causado por queda de objeto $(16,7 \%)$ e acidentes causados por objetos cortantes/perfurantes (16,7\%). Em 1994, acidentes causados por objetos cortantes/perfurantes foram os mais freqüentes entre os garis, representando $30,8 \%$ das causas neste ano, seguidos por acidentes com colisão com veículo a motor $(23,07 \%)$, queda no mesmo nível por escorregão/tropeção $(11,5 \%)$ e pisada em objeto estacionário (11,5\%).

Analisando-se os dois anos em conjunto, verificase que AT causados por objetos cortantes e/ou perfurantes foram os mais freqüentes. Esses dados são coincidentes com os encontrados por PEREIRA (1978) e ROBAZZI (1991), que detectaram acidentes causados por estes tipos de objetos, como sendo os mais produtores de lesões em garis e coletores de lixo. Ao realizar as tarefas de varrer os resíduos das ruas, recolhê-los com a pá e colocá-los em sacos plásticos para posteriormente depositá-los nos carrinhos, os trabalhadores cortam-se e/ou perfuram-se por materiais desta natureza, porque inadvertidamente os depositam nos sacos, provavelmente sem percebê-los. Outras vezes pisam em cacos de vidro e peças pontiagudas deixadas ao longo das ruas pela população. Estes fatos, adicionados ao não uso de luvas protetoras e sapatos adequados, favorece a ocorrência dos AT. A respeito da não utilização de equipamentos protetores, MARZIALE \& CARVALHO(1989) comentam que os varredores de rua atribuíram como causas principais de seus acidentes: a ausência de equipamentos de proteção individual, o uso de material inadequado, a falta de atenção do próprio trabalhador, a inexistência de segurança no trabalho e de experiência no serviço, entre outras.

Os acidentes por colisão com veículos a motor acontecidos durante o trabalho, nestes dois anos $(22,7 \%$ do total de 44 AT) podem ser explicados pelo fato dos trabalhadores estarem submetidos às condições contínuas de tráfego durante a maior parte do turno laboral, sendo encontradas, nas CAT pesquisadas, situações em que veículos albarroaram os trabalhadores e os carrinhos, fazendo com que caíssem ao chão e conseqüentemente, provocando-lhes AT. Desconhece-se, outrossim, qualquer campanha já veiculada, referente ao trânsito da cidade, que tenha levado em consideração as pessoas que realizam seu trabalho nas ruas, tais como vendedores, lixeiros, guardas-mirins e garis, entre outros. MARZIALE \& CARVALHO(1989) comentam que em Ribeirão Preto, existe grande número de carros circulando por ruas estreitas e não planejadas para absorver o fluxo de veículos que por elas trajetam continuamente. Sob essas ponderações, é compreensível entender o porque acontecem estes tipos de AT entre os varredores de ruas.

As quedas no mesmo nível ou de um nível a outro representaram, neste período, 15,9\% do total dos 44 AT.
Esses acidentes podem ter sido favorecidos pela situação de empurrar ou puxar o carrinho de lixo durante horas, em ruas com desníveis, nem sempre pavimentadas, o que provavelmente provoca cansaço nos trabalhadores, fazendo-os tropeçar e/ou escorregar durante o trajeto. Verificou-se também nas informações coletadas nas CAT, que objetos foram atirados nos trabalhadores, bem como evidenciaram-se situações em que eles foram empurrados (ao colidirem com bicicletas e/ou carros) sobre objetos e/ou pessoas, provocando as quedas.

Realizando o seu trabalho nas vias públicas, sob condições de trânsito, oras mais, oras menos intensa; recolhendo objetos perfurantes ou cortantes, atirados nas sarjetas pela população; empurrando ou puxando o carrinho coletor dos lixos em ruas, muitas vezes desniveladas; cansando-se provavelmente durante o turno laboral; sentindo desconforto pela ausência de sanitários próximos e/ou acesso à água para ingestão, acredita-se que a somatória destes fatores, acrescido de outros já comentados, possivelmente os favorece a sofrer os AT encontrados.

Para realização do levantamento das partes do corpo que foram lesadas, considerou-se nas CAT os itens "Descrição do acidente e parte(s) do corpo atingida(s)", bem como a "Descrição da(s) lesão(ões)" e "Diagnóstico provável", isto porque em algumas delas, alguns desses tópicos encontravam-se incompletos ou mesmo inexistentes, necessitando ser complementado pelos outros dois. Com base nesse levantamento, elaborou-se as tabelas a seguir:

Tabela 4 - Distribuição de 18 AT entre 18 empregados da varrição das ruas da cidade de Ribeirão Preto (SP) em relação às partes do corpo atingidas no ano de 1993

\begin{tabular}{lcc}
\hline PARTES DO CORPO ATINGIDAS & $\mathrm{N}^{\circ}$ & $\%$ \\
\hline MEMBROS INFERIORES & 10 & 55,5 \\
MEMBROS SUPERIORES & 4 & 22,2 \\
MULTIPLAS PARTES & 3 & 16,7 \\
TRONCO & 1 & 05,5 \\
\hline TOTAL & 18 & 99,9 \\
\hline
\end{tabular}

Tabela 5 - Distribuição de 26 AT entre 26 empregados da varrição das ruas da cidade de Ribeirão Preto (SP) em relação às partes do corpo atingidas no ano de 1994

\begin{tabular}{lcc}
\hline PARTES DO CORPO ATINGIDAS & $\mathrm{N}^{\circ}$ & $\%$ \\
\hline MEMBROS INFERIORES & 12 & 46,1 \\
MEMBROS SUPERIORES & 07 & 26,9 \\
MULTIPLAS PARTES & 04 & 15,4 \\
CABECA & 02 & 07,7 \\
TRONCO & 01 & 03,8 \\
\hline TOTAL & 26 & 99,9 \\
\hline
\end{tabular}


As informações destes dois anos, em relação a parte do corpo lesada, encontram-se demonstradas na figura a seguir:

Figura 2 - Distribuição de 44 AT entre 44 garis acidentados de acordo com as partes do corpo lesadas nos anos de 1993 a 1994

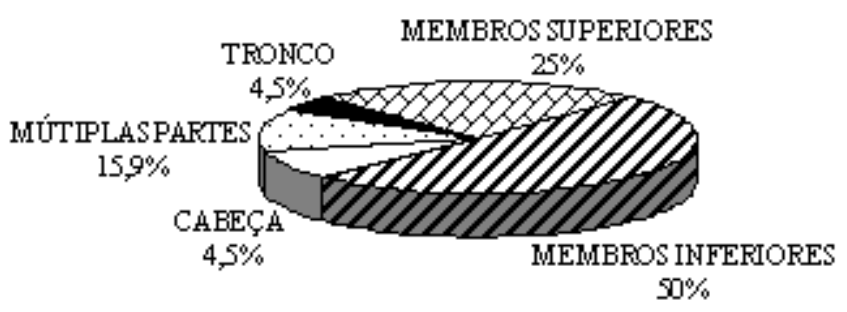

Observa-se que os membros inferiores foram os mais atingidos durante os AT, seguidos pelos superiores. Em estudo realizado por PEREIRA (1978) com os empregados da limpeza urbana da cidade do Rio de Janeiro (RJ), o autor demonstrou que essas duas regiões foram também as mais acometidas, particularmente mãos e pés. Os dados encontrados no presente estudo são igualmente concordantes com os encontrados por MARZIALE \& CARVALHO (1989). Estes autores relacionam a elevada incidência de lesões em membros inferiores à atividade executada pelos garis, pois ao percorrer grandes distâncias diariamente terminam por expor muito essa região do corpo. SILVA (1983) igualmente observou que os membros inferiores foram os mais lesados no estudo que realizou entre varredores de rua, da cidade de São Paulo.

Como a empresa contratante dos garis declarou que não fornece equipamentos de proteção individual aos seus empregados, estes AT podem ter ocorridos devido a não distribuição de sapatos adequados, acrescido à distancia percorrida cotidianamente, durante o turno laboral. Quanto aos membros superiores, estes são requisitados durante todo tempo e acabam sendo facilmente atingidos por materiais pérfuro-cortantes e outras causas. O não uso de equipamentos de segurança adequados (luvas) possivelmente ainda agrava mais a situação.

\section{CONCLUSÕES E RECOMENDAÇÕES}

O trabalho dos varredores de rua é considerado insalubre, em decorrência dos agentes biológicos presentes nos lixos recolhidos; é realizado a "descoberto", em praças, ruas e demais logradouros públicos. Este fato faz com que os trabalhadores submetam-se às variações climatológicas, ruídos, poeiras e outros agentes agressores, que lhes podem favorecer a ocorrência de enfermidades e acidentes de trabalho.

$\mathrm{Na}$ cidade de Ribeirão Preto, Estado de São Paulo, levantou-se 44 acidentes registrados, acontecidos entre 44 garis, referentes aos anos de 1993 e 1994. Estas pessoas eram empregadas de uma empresa particular e provavelmente o reduzido número de acidentes encontrados, foram subnotificados. Constatou-se que a maior parte dos mesmos era "acidente tipo", causados, em sua maioria, por objetos cortantes e/ou perfurantes, colisões com veículos e quedas dos trabalhadores. As partes do corpo mais agredidas foram os membros inferiores, seguidos dos superiores. Em decorrência das informações prestadas pela empresa contratante destes indivíduos, observou-se que não utilizam luvas ou sapatos apropriados para realizar o seu trabalho.

Os resultados foram apresentados à empresa, com algumas recomendações, entre elas a que proporcionasse maior atenção ao trabalho dos garis e lhes fornecesse luvas e calçados adequados, para a realização de seu serviço. Sugeriu-se o desenvolvimento de uma campanha em nível da cidade, orientando a população a separar adequadamente os resíduos, não jogando objetos cortantes/perfurantes nas ruas. O setor responsável pelo trânsito urbano igualmente deveria ser avisado sobre os atropelamentos dos garis pelos veículos, enquanto executam as suas tarefas nas vias públicas. Os resultados foram comentados também com o Escritório Regional de Saúde local, cujos membros, legalmente, podem exercer função fiscalizadora sobre a empresa, advertindoa e também a assessorando a respeito dos acidentes e da falta de qualidade, relativa à condições laborais dos varredores de ruas.

\section{STREET ORDERLIES: OCCUPATIONAL ACCIDENTS OCCURRED IN THE CITY OF RIBEIRÃO PRETO, STATE OF SÃO PAULO, BRAZIL}

The work of street sweepers is to sweep waste materials thrown at public streets. It is considered insalubrious due to the close contact that exposes workers to agents present in the urban waste. As street orderlies perform their duties in an open environment, they are submitted to different types of problems. The purpose of this study is to investigate the registered occupational accidents occurred among street orderlies in the city of Ribeirão Preto, State of São Paulo, during 1993 and 1994. Authors aimed at verifying: the number of works that suffered accidents and the notified occupational accidents; data related to the identification of those accidents at the employer company and specific data regarding the occupational accidents. Therefore, authors analyzed the occupational health reports recorded at the National Institute of Social Security at the Regional Bureau of Health (RBH) and 
at the employer company. Results were shown to the employers and to the RBH. Authors organized meetings to discuss with them the occupational problems they found.

KEY WORDS: street orderlies, occupational accidents

\section{BARREDORES DE LA CALLE: ACCIDENTES DE TRABAJO OCURRIDOS EN LA CIUDAD DE RIBEIRÃO PRETO, PROVINCIA DE SÃO PAULO, BRASIL}

El trabajo de los barredores es recoger los detritus y acúmulus presentes en las calles. Este trabajo es insalubre, por el contacto íntimo, lo cual expone a los trabajadores a agente presentes en la basura urbana. Como realizan sus tareas en ambientes abiertos, se encuentran sometidos a varios tipos de agresiones. El presente estudio tuvo el objetivo general de investigar los accidentes de trabajo registrados, ocurridos entre barredores, en la ciudad de Ribeirão Preto, Província de São Paulo, durante los años de 1993 y 1994. Como objetivos específicos, los autores pretendieron verificar el número de trabajadores accidentados, accidentes de trabajo notificados, datos de identificación personal y empresarial y los datos específicos de los accidentes de trabajo. Para el logro de los objetivos, fueron analizadas las informaciones contenidas en las notificaciones de accidentes de trabajo archivadas en el Intituto Nacional de Seguridad Social, en la Oficina Regional de Salud (ERSA) local y en la empresa de limpieza urbana empleadora de barredores. Los resultados fueron dados a conocer al empleador y al ERSA y los autores se colocaron a disposición para discutir en conjunto soluciones para los problemas ocupacionais encontrados.

TÉRMINOS CLAVES: barredores, accidentes de trabajo

\section{REFERÊNCIAS BIBLIOGRÁFICAS}

01. ALMEIDA, I.M.; BINDER, M.C.; TOLOSA, D.E.R. Acidentes do trabalho no município de BotucatuSP,1990. Rev. Bras. Saúde Ocup., v. 21, nº 80, p.29-41, out/nov/dez. 1994.

02. BRASIL. Ministério do Trabalho. Classificação brasileira de ocupações (CBO). Brasília, 1982. p. 213.

03. BULHÕES, I. Os acidentes de trabalho. In: BULHÕES, I. Enfermagem do trabalho. Rio de Janeiro: Luna, 1976. v. 1, cap. 7, p. 149-158.

04. FERREIRA, A.B.H. Minidicionário Aurélio da língua portuguesa. $3^{\mathrm{a}}$ ed. Rio de Janeiro: Nova Fronteira, 1993. 577p.

05. MACEDO, M.A. A responsabilidade pública pela saúde do trabalhador. In: CONFERÊNCIA NACIONAL DA SAÚDE, 7, Brasília, 1980. Anais. Brasília: Ministério da Saúde/ Serviços Básicos de Saúde, 1980. p.45-48.

06. MARZIALE, H.P.M.; CARVALHO, E.C. Riscos ocupacionais em limpeza urbana: varreção das ruas. Rev. Gaúch. Enfermagem, Porto Alegre, v.10, n. 1, p. 71-81, jan. 1989.

07. MEDRADO-FARIA, M.A. Saúde e trabalho industrial: condições de saúde dos operários brasileiros. Ci. Cult., v.40, n. 10, p. 967-975, 1988.

08. MENDES, R. Doutrina e prática de integração da saúde ocupacional no setor saúde: contribuição para a definição de uma política. São Paulo, 1986. Tese (Livre Docência) - Faculdade Saúde Pública, Universidade de São Paulo.
09. OLIVEIRA,C.A.B. As relações de trabalho têm que se modernizar O Estado de São Paulo, 7 de agosto 1994. p.H33.

10. PEREIRA, A.S.O. Acidente de trabalho em limpeza urbana. Rio de Janeiro: COMLURB, 1978. v. 1, p. 1- 24 .

11. PINTO, M.S. A coleta e disposição do lixo no Brasil. Rio de Janeiro: Fundação Getúlio Vargas, 1979.

12. POSSAS, C.A. Avaliação da situação atual do sistema de informação sobre doenças e acidentes do trabalho no âmbito da previdência social brasileira e propostas para sua reformulação. Rev. Bras. Saúde Ocup., v.15, n. 60, p. 43-67, 1987.

13. ROBAZZI,M.L.C.C. Estudo das condições de vida, trabalho e riscos ocupacionais a que estão sujeitos os coletores de lixo da cidade de Ribeirão Preto Estado de São Paulo. Ribeirão Preto, 1984. 120p. Dissertação(Mestrado) Escola de Enfermagem de Ribeirão Preto, Universidade de São Paulo.

14. ROBAZZI, M.L.C.C. Contribuição ao estudo sobre coletores de lixo: acidentes de trabalho ocorridos em Ribeirão Preto, Estado de São Paulo, no período de 1986 a 1988. Ribeirão Preto, 1991.p. 22-36. Tese (Doutorado) - Escola de Enfermagem de Ribeirão Preto, Universidade de São Paulo.

15. SANTOS, U. P. et al. Sistema de vigilância epidemiológica para acidentes de trabalho: uma experiência na Zona Norte do município de São Paulo (Brasil). Rev. Saúde Pública, São Paulo, v. 24, n 4, p. 286-93, 1990. 
16. SEGURANÇA e medicina do trabalho. São Paulo: Atlas, 1995. p.188-189. (Coleção Manuais de Legislação).

17. SEWELL, G.H. A importância dos resíduos sólidos. In: SEWELL, G.H. Administração e controle da qualidade ambiental. São Paulo: EPU/ EDUSP/Cetesb, 1978. cap.11, p.216-229.

18. SHIMO, A.K.K. Sanitário portátil: uma contribuição para as varredoras de rua. Ribeirão Preto, 1995. Tese (Doutorado) - Escola de Enfermagem de Ribeirão Preto, Universidade de São Paulo.
19. SILVA, E.P. Condições de saúde ocupacional dos lixeiros de São Paulo. Rev. Bras. Saúde Ocup., v.11, no 42, p. 30-40, abril/maio/junho 1983.

20. STELMAN, J.M.; DAUM, S.M. Trabalho e saúde na indústria: riscos físicos e químicos na prevenção de acidentes. São Paulo: EPU/ EDUSP, 1975. p. 126-131.

21. WINGAARDEN, J.B.; SMITH, L.H. Tratado de medicina interna. $18^{\mathrm{a}}$ ed. Rio de Janeiro: Guanabara, 1988. v. 2, cap. 541, p. 2092. 